\title{
PET study in a patient with spinocerebellar degeneration before and after long-term administration of thyrotropin releasing hormone
}

\author{
H. Tanji ${ }^{1}$, H. Nagasawa ${ }^{1}$, T. Hayashi ${ }^{1}$, H. Onodera', T. Fujiwara ${ }^{2}$, M. Itoh², T. Ido \\ and Y. Itoyama ${ }^{1}$ \\ ${ }^{1}$ Department of Neurology, Tohoku University School of Medicine, and ${ }^{2}$ Cyclotron and \\ Radioisotope Center, Tohuku University, Sendai, Japan \\ Correspondence to: H. Tanji, Department of Neurology, Tohoku University School of Medicine, \\ 1-1 Seiryo-machi, Aoba-ku, Sendai 980-77, Japan
}

\begin{abstract}
We studied the chronic effect of thyrotropin releasing hormone (TRH) in a patient with spinocerebellar degeneration by measuring cerebral metabolic rate for glucose (CMRG1c) using $2-\left[{ }^{18}\right.$ F $]$ fluoro-2-deoxy-D-glucose $\left({ }^{18}\right.$ FDG) and positron emission tomography (PET). A 56-year-old female, who had suffered from progressive ataxia for 2 years, was treated by intravenous administration of $2 \mathrm{mg}$ TRH for 3 weeks, and CMRG1c of the brain was measured before and after treatment. CMRG1c was markedly decreased in the cerebellum and there was no significant difference before and after the treatment, i.e. mean CMRG1c values were 4.92 and $4.90 \mathrm{mg} / 100 \mathrm{~g} / \mathrm{min}$, and the ratios of the cerebellum versus the frontal cortex were 0.50 and 0.51 , respectively. The degree of disequilibrium of her body examined with stabilography became better by the 19th day and further improved by the 26th day after the start of TRH treatment. Based on the present study we conclude that long-term administration of TRH did not improve CMRG1c in the cerebellum, but evidently improved the sway of gravity center by stabilography. We speculate that the chronic effect of TRH was not necessarily due to an improvement of cerebellar function, because TRH receptors are widely distributed throughout the central nervous system.
\end{abstract}

Keywords: Cerebral glucose metabolism - Positron emission tomography - Spinocerebellar degeneration - Thyrotropin releasing hormone

\section{INTRODUCTION}

Several positron emission tomographic (PET) studies in patients with spinocerebellar degeneration (SCD) have demonstrated a decrease in regional blood flow and metabolic rate for glucose in the cerebellum (Gilman et al., 1988; Harada et al., 1988; Kluin et al., 1988; Rosenthal et al., 1988; Sakai et al., 1989; Kondo et al., 1993), and some report that the degree of glucose hypometabolism was correlated to the clinical severity of SCD (Kluin et al., 1988; Rosenthal et al., 1988). On the other hand, there have been few studies to evaluate the effect of thyrotropin releasing hormone (TRH) by using PET, although TRH has been widely used for treatment of SCD (Sobue et al., 1980, 1983; Kimura et al., 1983; Yoshida et al., 1986). Harada et al. (1988) described the increase of cerebellar blood flow immediately after intravenous TRH administration, but the chronic effect of long-term administration was not discussed. In the present study, we evaluated the chronic effect of TRH thera- py by measuring cerebral metabolic rate for glucose (CMRGlc) in a patient with SCD using $2-\left[{ }^{18} \mathrm{~F}\right]$ fluoro-2-deoxy-D-glucose $\left({ }^{18} \mathrm{FDG}\right)$ and PET.

\section{METHODS}

\section{Subject}

A 56-year-old female developed slowly progressive gait instability and speech disturbance over 2 years. There was no remarkable past illness or family history of SCD. On admission in 1994, neurological examination revealed saccadic eye movement, horizontal nystagmus, ataxic speech, moderate truncal ataxia and marked incoordination in four limbs with no pyramidal and extra-pyramidal tract signs, but involuntary movement or dementia was not observed. The general laboratory data, thyroid function, tumor markers and cerebrospinal fluid examination were 


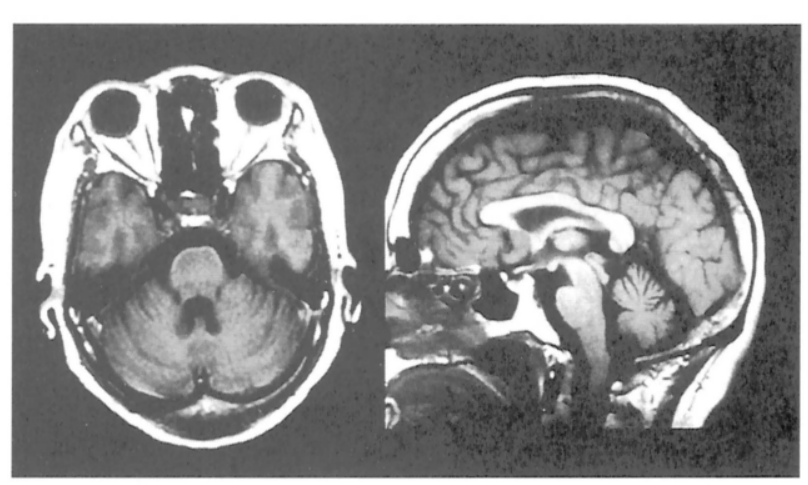

FIG. 1. MRI (T1-weighted image) revealed marked atrophy in both cerebellar hemispheres and vermis, and slight atrophy in the brainstem.

normal. Nerve conduction velocities in four limbs and an electroencephalogram were also normal. However, she was involved in mild autonomic dysfunction, because the coefficient of variation of R-R interval in ECG was slightly reduced $(2.53 \%$ on average). Gallium scintigraphy of the whole body showed no abnormality. Magnetic resonance images (MRI) of the brain revealed marked atrophy in both cerebellar hemispheres and vermis, and slight atrophy in the brainstem (Fig. 1).

\section{Procedure}

The patient was diagnosed as having a sporadic type of SCD by her clinical symptoms and MRI findings. For the treatment, $2 \mathrm{mg}$ TRH were administered intravenously everyday. Regional CMRGlc of the brain was measured by PET using ${ }^{18} \mathrm{FDG}$ before and 3 weeks after the TRH treatment.

The study was approved by the Research Ethics Committee of the Tohoku University, School of Medicine. The patient gave her written informed consent. The PET study was performed with a model PT931 scanner (CTI Inc., USA), according to the FDG method (Phelps et al., 1979; Reivich et al., 1979) at the Cyclotron and Radioisotope Center, Tohoku University, Sendai, Japan. Before the study, a short 21-gauge cannula was placed in a brachial artery

TABLE I. Mean values and ratios of metabolic rate for glucose in cerebellum and frontal cortex before and after TRH treatment

\begin{tabular}{lcrr}
\hline & Before TRH & After TRH Control' \\
\hline Cerebellum & 4.92 & 4.90 & $7.02 \pm 1.89$ \\
Frontal cortex & 9.76 & 9.60 & $8.30 \pm 2.01$ \\
\hline Cerebellum: frontal cortex & 0.50 & 0.51 & \\
\hline
\end{tabular}

Values are mean \pm S.D. $(\mathrm{mg} / 100 \mathrm{~g} / \mathrm{min})$ from six normal subjects (mean age 63.3 years). under local anesthesia for arterial blood sampling. The patient was then positioned in the scanner, with the orbitomeatal (OM) line parallel to the detector ring. A cross of light was projected onto markers on her head from three dimensions, and the head was set at the standard points of 16,63 and $110 \mathrm{~mm}$ above and parallel to the OM line. The study was conducted in a quiet, semi-darkened room. Before the emission scanning, a 15-min transmission scan using a ${ }^{68} \mathrm{Ge}-{ }^{68} \mathrm{Ga}$ external ring source was performed. ${ }^{18} \mathrm{FDG}$ was synthesized according to the method of Ido et al. (1977). ${ }^{18}$ FDG (96.2 Mbq 1st study, 115.4 Mbq 2nd study) was injected as an intravenous bolus. Thirty to $60 \mathrm{~min}$ after the injection, a series of three emission scans were performed by using a PT-931 with an $8 \mathrm{~mm}$ axial and transaxial resolution at the center of each standard point. Each emission datum was simultaneously collected from seven contiguous axial sections. A total of 21 slices parallel to the OM line with a slice thickness of $6 \mathrm{~mm}$, encompassing virtually the whole brain including the cerebellum, were analyzed. Twenty blood samples were collected from the brachial artery according to the following protocol: from injection to $2 \mathrm{~min}$, one sample every $20 \mathrm{~s}$, then samples at 2.5, 3, 4. 5, 7.5, 10, 15, 20, 25, 30, 40, 50, and $60 \mathrm{~min}$ after the intravenous administration of ${ }^{18}$ FDG. The blood plasma radioactivities of ${ }^{18} \mathrm{FDG}$ were measured with a cross-calibrated well-counter.

Values of regional CMRGlc were calculated using the operational equation derived by Phelps et al. (1979) and Huang et al. (1980) from that of Sokoloff et al. (1977).

Eighty-four regions of interest (ROIs) (circular region of $1.93 \mathrm{~cm}^{2}$ ) were placed on the cerebellum and the frontal cortex (20 ROIs on the cerebellum of four slices, 64 ROIs on the frontal cortex of all nine slices traversing the frontal lobe), and the mean value of CMRGlc of each structure was calculated.

We also examined the sway of gravity center of her body unbalanced by truncal ataxia using stabilography at the 19th and 26th day of the TRH treatment.

TABLE II. Areas of sway of gravity center of the patient measured by stabilography before and after TRH treatment.

\begin{tabular}{lccc}
\hline \multirow{2}{*}{ Before TRH } & \multicolumn{2}{c}{ After TRH } & Control' \\
\cline { 2 - 3 } & 19th day & 26th day & \\
\hline 27.94 & 8.95 & 4.94 & $1.90 \pm 0.76$ \\
\hline
\end{tabular}

Values are mean \pm S.D. $\left(\mathrm{cm}^{2}\right)$ from 31 normal subjects. 


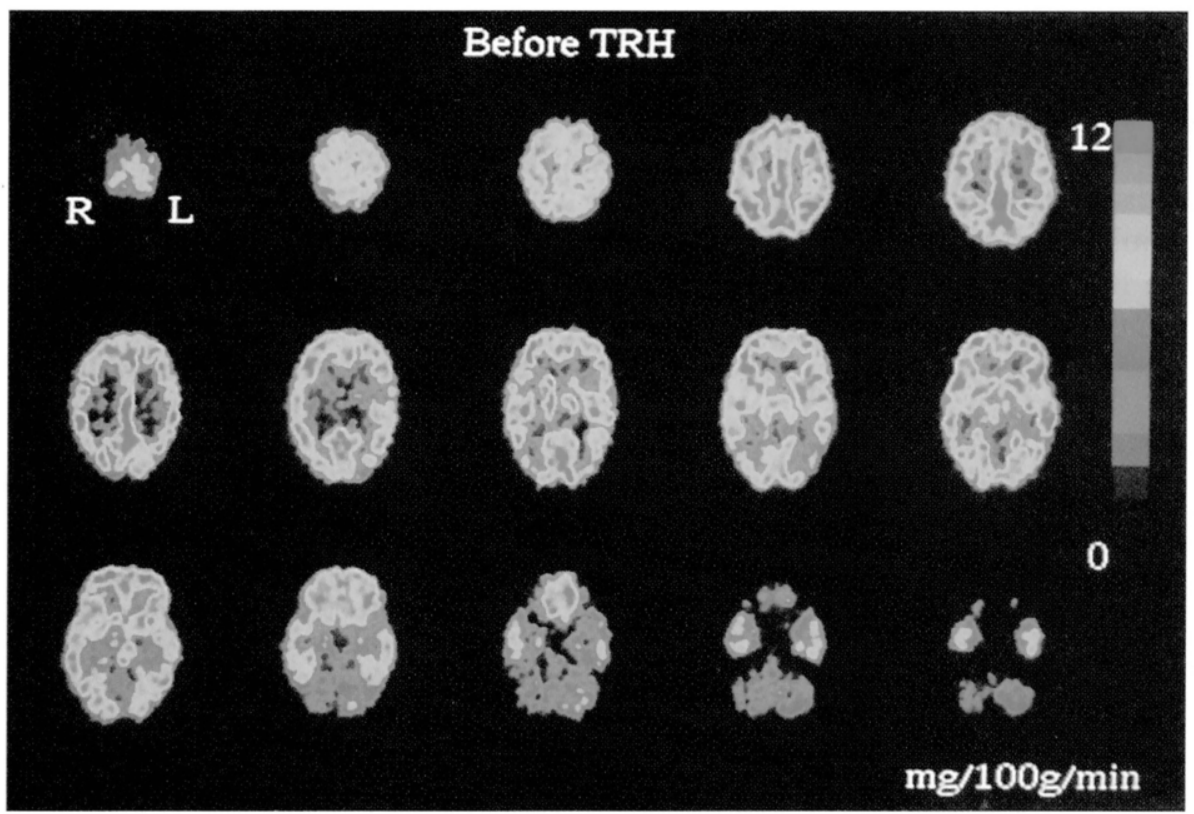

FIG. 2. PET images of the cerebral metabolic rate for glucose (CMRGIc) using $\left({ }^{18} \mathrm{FDG}\right)$ before TRH treatment. CMRGIc was markedly decreased in the cerebellum. In the other regions of the brain, regional CMRGIc was almost normal and there was no difference between right and left hemispheres with focal abnormality.

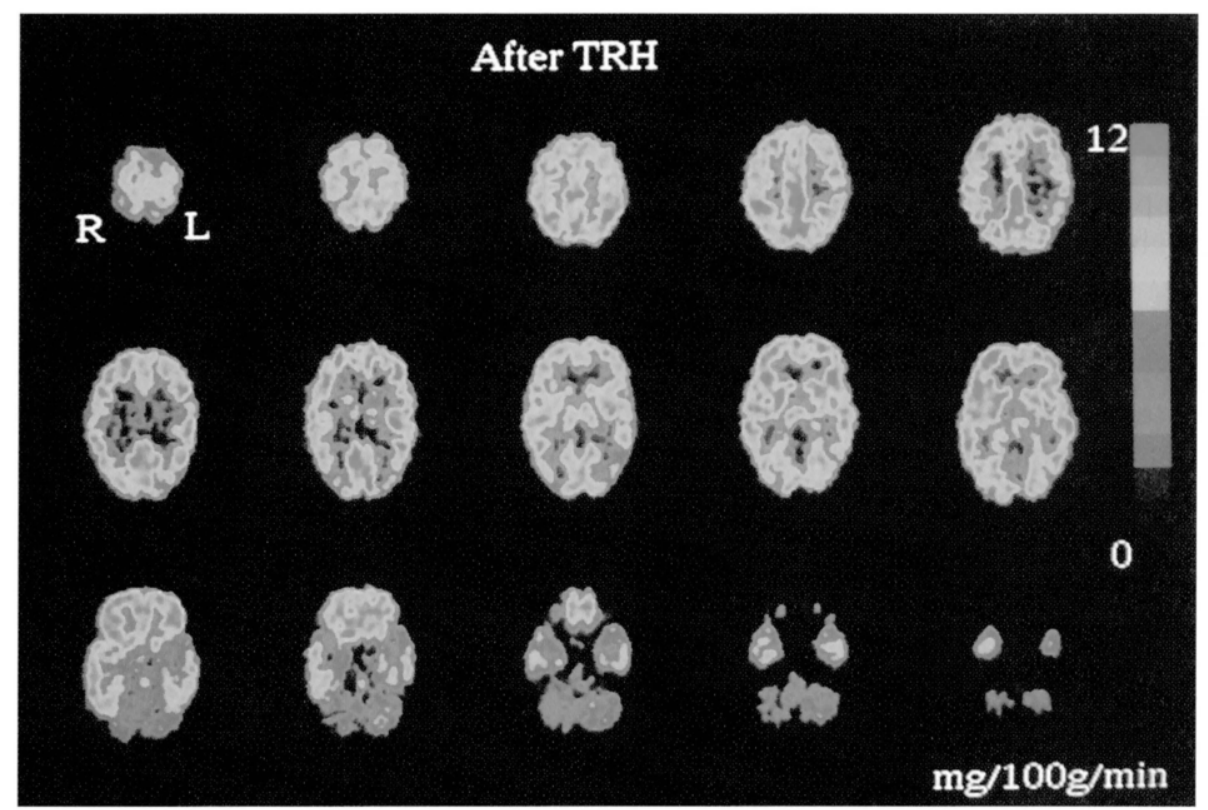

FIG. 3. PET images of the metabolic rate for glucose 3 weeks after the TRH treatment. A marked decrease of CMRGIc in the cerebellum was still observed.

\section{RESULTS}

Before the TRH treatment, CMRGlc was markedly decreased in the cerebellum. In the other regions of the brain, CMRGlc was almost normal and there was no difference between hemispheres with focal abnormality (Fig. 2). A marked decrease of CMRGlc in the cerebellum was also observed 3 weeks after the TRH treatment (Fig. 3). The mean values of CMRGlc in the cerebellum were 4.92 and $4.90 \mathrm{mg} / 100 \mathrm{~g} / \mathrm{min}$, and the ratios of the cerebellum versus the frontal cortex were 0.50 and 0.51 before and after the TRH treatment, respectively (Table I). Thus there was not significant change of CMRGlc in the cerebellum after TRH treatment in this patient. 
Clinically, although her gait instability and gait speed were slightly improved after the TRH treatment, the limb coordination, such as finger-to-nose test and heel-to-knee test, did not clearly improve. However, on examination with stabilography, the degree of disequilibrium of her body when she was standing on the floor became better by the 19th day of the TRH treatment, and was further improved by the 26th day (Table II).

\section{DISCUSSION}

In previous studies, values of CMRG1c were significantly reduced in the cerebellar hemispheres and vermis in patients with SCD (Gilman et al., 1988; Kluin et al., 1988; Rosenthal et al., 1988). However, marked atrophy was also observed in most patients by MRI, and it was speculated that hypometabolism in the cerebellum might be explained by partial volume effects. In some cases with slight atrophic change of the cerebellum, regional CMRGlc was reduced significantly (Gilman et al., 1988). It is suggested that glucose hypometabolism of the cerebellum may be explained not only by the cerebellar atrophy but also by neuronal dysfunction of the cerebellum itself. In the present study, the significant decrease of CMRGlc in the cerebellum was observed in accordance with the previous reports. This may be due to both atrophic changes and neuronal dysfunction of the cerebellum.

TRH has been widely used for treatment of patients with SCD. It has been suggested that the mechanism of the TRH effect may be related to the improvement of abnormal noradrenaline metabolism in the cerebellum (Sobue et al., 1980; Arai, 1988), but the details are still unknown. A few reports using PET or SPECT described an increase of cerebellar blood flow immediately after intravenous TRH administration (Harada et al., 1988; Ono et al., 1988), so cerebellar function might improve a short time after administration. However, the administrated TRH is rapidly metabolized in the blood, and mechanisms of the chronic effects are unknown. In the present study, we evaluated the chronic effects of TRH therapy and also investigate the mechanism by PET. In order to exclude the influence of cerebral blood flow, we calculated the ratios of the cerebellum versus the frontal cortex as a reference area, because TRH receptor binding sites are at relatively low levels in the frontal cortex (Manaker et al., 1986). In conclusion, we found that TRH did not improve CMRGlc in the cerebellum, but evidently improved the sway of gravity center by stabilography with no significant changes of neurological findings. We speculate on the reason why the effect of TRH was too small to obtain improvement of cerebellar glucose metabolism with PET. We also speculate that the effect of TRH was not necessarily due to an improvement of cerebellar function, because TRH receptors are widely distributed throughout the central nervous system (Manaker et al., 1986). A further detailed study is needed to clarify the mechanism of pharmacological action of TRH in patients with SCD.

\section{REFERENCES}

Arai M (1988) Amine metabolites in cerebrospinal fluids and thyrotropin releasing hormone in spinocerebellar degeneration. Clinical Neurology, 28, 595-604.

Gilman S, Markel DS, Koeppe RA, et al (1988) Cerebellar and brainstem hypometabolism in olivopontocerebellar atrophy detected with positron emission tomography. Annals of Neurology, 23, 233-230.

Harada K, Fukuyama H, Miyoshi T, et al (1988) Alteration of $\mathrm{CBF}$ and $\mathrm{CMRO}_{2}$ and TRH effects on $\mathrm{CBF}$ in spinocerebellar degeneration. The PET study. Clinical Neurology, 28, 563-568.

Huang SC, Phelps ME, Hoffman EJ, et al (1980) Noninvasive determination of local cerebral metabolic rate of glucose in man. American Journal of Physiology, 238, E69-E82.

Ido T, Wan CN, Fowler JS, et al (1977) Flourination with F2, a convenient synthesis of 2-fluoro-2-deoxy-D-glucose. Journal of Organic Chemistry, 42, 2341-2342.

Kimura I, Ohtomo H and Kogure K (1983) Motor disabilities and effects of thyrotropin-releasing hormone on ataxia of spinocerebellar degeneration. Tohuku Journal of Experimental Medicine, 139, 331-337.

Kluin KJ, Gilman S, Markel DS, et al (1988) Speech disorders in olivopontocerebellar atrophy correlate with positron emission tomography findings. Annals of Neurology, 23, 547-554.

Kondo S, Tanaka M, Sun X, et al (1993) Study of patients with spinocerebellar degeneration using positron emission tomography. Clinical Neurology, 33, 1039-1046.

Manaker S, Eichen A, Winokur A, et al (1986) Autoradiographic localization of thyrotropin releasing hormone receptors in human brain. Neurology, 36, 641-646.

Ono S, Fukunaga M, Otsuka N, et al (1988) Single photon emission computed tomography using $\mathrm{N}$-isopropyl-p$\left.{ }^{123} \mathrm{I}\right]$-iodoamphetamine in spinocerebellar degeneration. Japanese Journal of Nuclear Medicine, 25, 393-403.

Phelps ME, Huang SC, Hoffman EJ, et al (1979) Tomographic measurement of local cerebral glucose metabolic rate in human with [F-18]2-fluoro-2-deoxy-Dglucose: validation of method. Annals of Neurology, 6, 371-388.

Reivich M, Kuhl D, Wolf AP, et al (1979) The ${ }^{18}$ F-fluorodeoxyglucose method for the measurement of local cerebral glucose utilization in man. Circulation Research, 44, 127-137.

Rosenthal G, Gilman S, Koeppe RA, et al (1988) Motor dysfunction in olivopontocerebellar atrophy is related to 
cerebral metabolic rate studied with positron emission topography. Annals of Neurology, 24, 414-419.

Sakai Y, Shouji M, Ishihara T, et al (1989) Analysis of cerebellar functions in spinocerebellar degeneration using positron emission tomography (PET). Clinical Neurology, 29, 284-289.

Sobue I, Yamamoto H, Konagaya M, et al (1980) Effect of thyrotropin-releasing hormone on ataxia of spinocerebellar degeneration. Lancet, 23, 418-419.

Sobue I, Takayanagi T, Nakanishi T, et al (1983) Controlled trial of thyrotropin releasing hormone tartrate in ataxia of spinocerebellar degenerations. Journal of Neurological Sciences, 61, 235-248.

Sokoloff L, Reivich M, Kennedy C, et al (1977) The $\left[{ }^{14} \mathrm{C}\right]$ deoxyglucose method for the measurement of local cerebral glucose utilization: theory, procedure, and normal values in the conscious and anesthetized albino rat. Journal of Neurochemisty, 28, 897-916.

Yoshida M, Nakanishi T and Komatsu Y(1986) Acute and chronic effects of thyrotropin-releasing hormone (TRH) on stabilogram in spinocerebellar degenerations. Tohoku Journal of Experimental Medicine, 148, 327-331. 


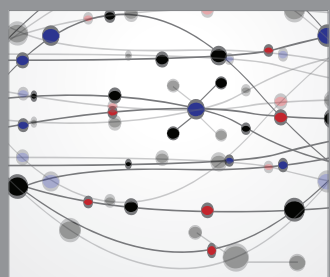

The Scientific World Journal
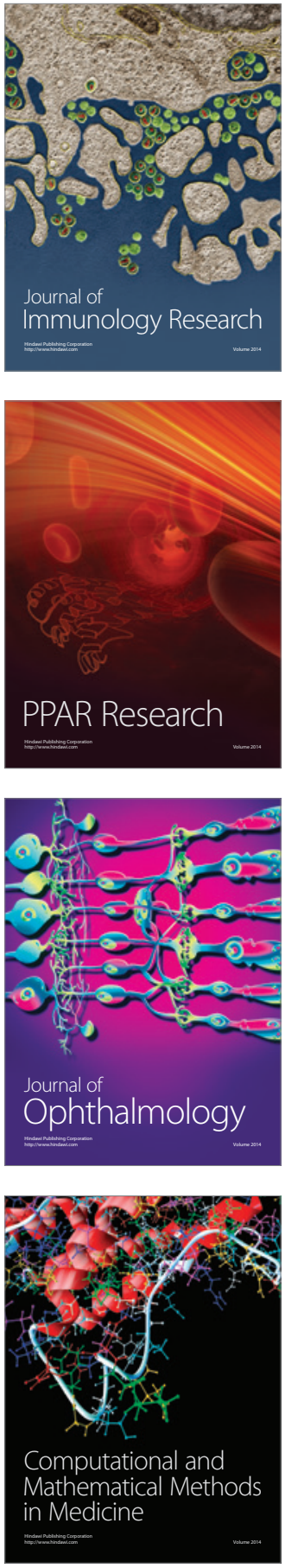

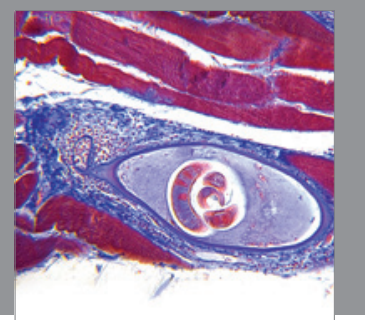

Gastroenterology

Research and Practice
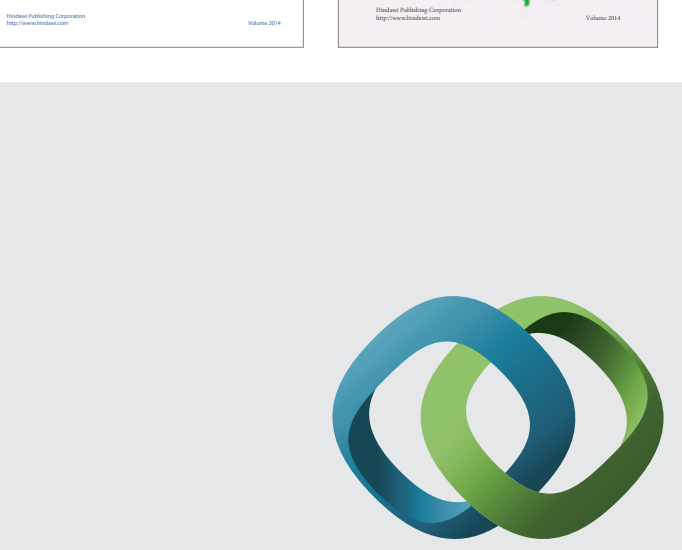

\section{Hindawi}

Submit your manuscripts at

http://www.hindawi.com
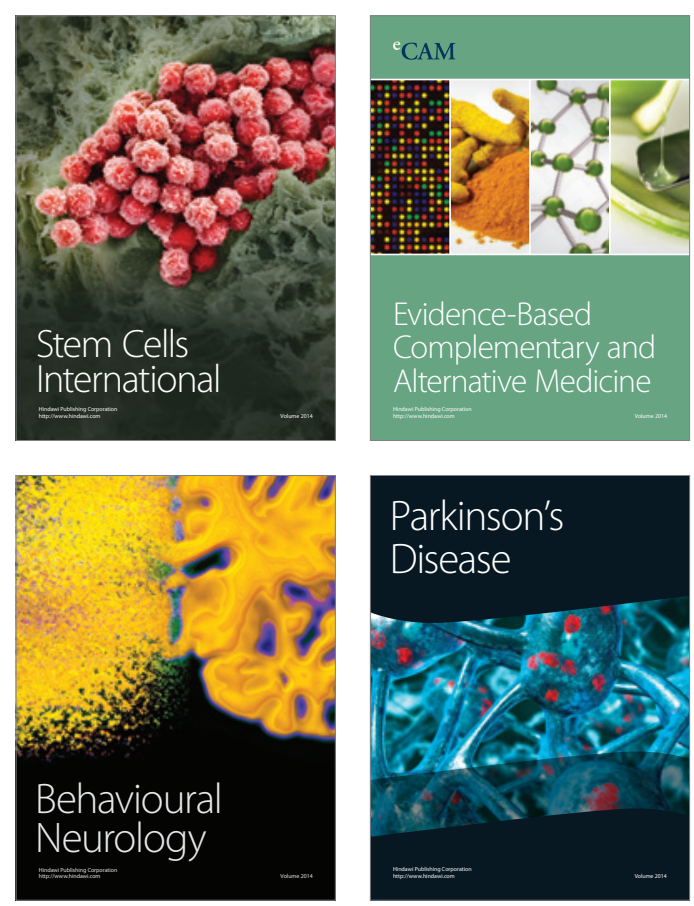

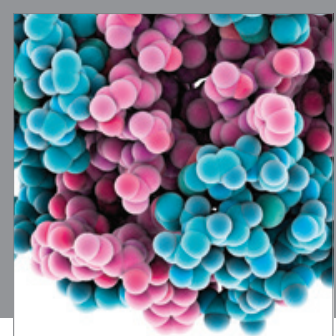

Journal of
Diabetes Research

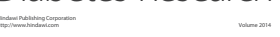

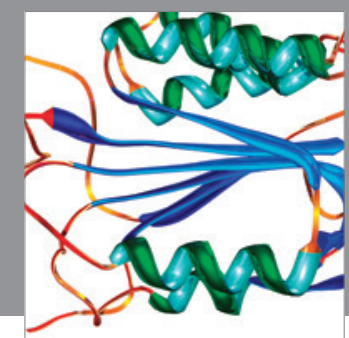

Disease Markers
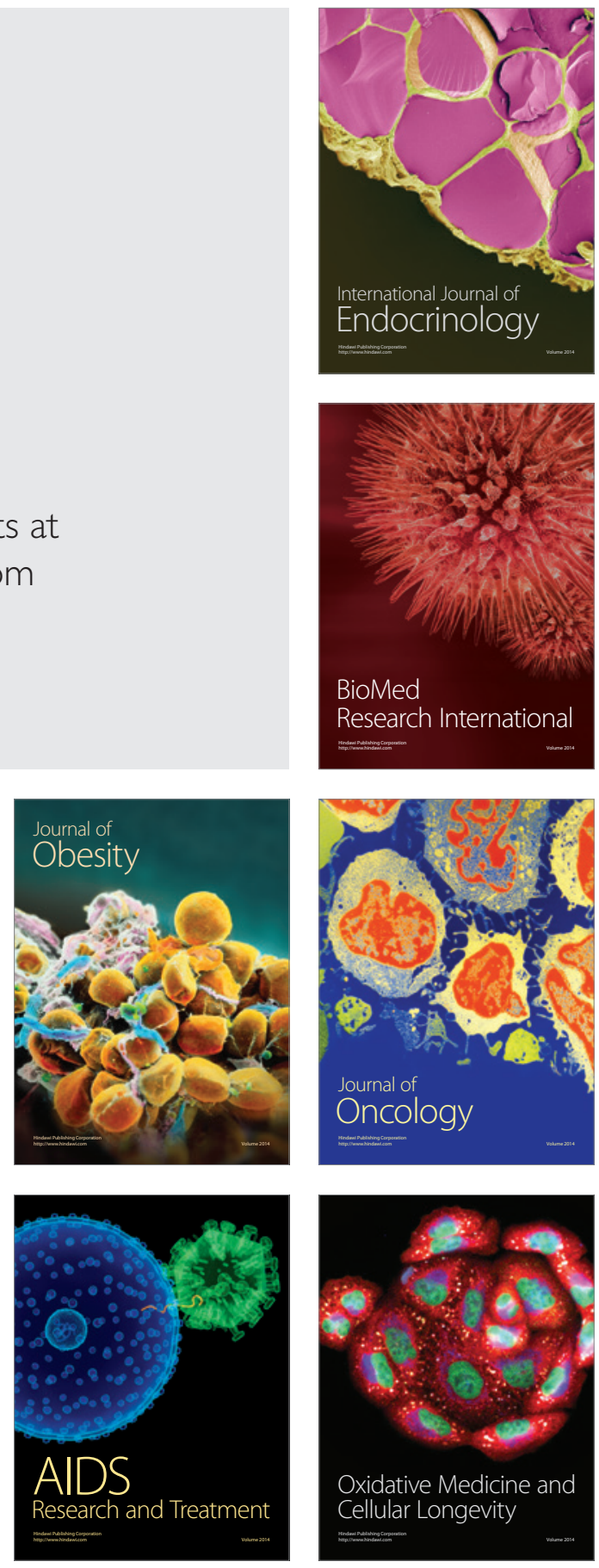